\title{
Multiwalled Carbon Nanotubes Decorated with Cobalt Oxide Nanoparticles
}

\author{
D. G. Larrude, ${ }^{1}$ P. Ayala, ${ }^{2}$ M. E. H. Maia da Costa, ${ }^{1}$ and F. L. Freire Jr. ${ }^{1}$ \\ ${ }^{1}$ Departmento de Física, Pontifícia Universidade Católica do Rio de Janeiro, 22451-900 Rio de Janeiro, RJ, Brazil \\ ${ }^{2}$ Faculty of Theoretical Physics, University of Vienna, Strudlhofgaße 4, A-1090, Vienna, Austria
}

Correspondence should be addressed to F. L. Freire Jr., lazaro@vdg.fis.puc-rio.br

Received 7 December 2011; Accepted 18 January 2012

Academic Editor: Chunyi Zhi

Copyright ( 2012 D. G. Larrude et al. This is an open access article distributed under the Creative Commons Attribution License, which permits unrestricted use, distribution, and reproduction in any medium, provided the original work is properly cited.

\begin{abstract}
Multiwalled carbon nanotubes (MWCNTs) synthesized by spray pyrolysis were decorated with cobalt oxide nanoparticles using a simple synthesis route. This wet chemistry method yielded nanoparticles randomly anchored to the surface of the nanotubes by decomposition of cobalt nitrate hexahydrate diluted in acetone. Electron microscopy analysis indicated that dispersed particles were formed on the MWCNTs walls. The average size increased with the increasing concentration of cobalt nitrate in acetone in the precursor mixture. TEM images indicated that nanoparticles were strongly attached to the tube walls. The Raman spectroscopy results suggested that the MWCNT structure was slightly damaged after the nanoparticle growth.
\end{abstract}

\section{Introduction}

Carbon nanotubes are receiving an increasing scientific interest because of their remarkable properties. They exhibit an extraordinary mechanical strength, and electrical, chemical and thermal characteristics, making them useful for several potential applications $[1,2]$. In the last years, because of their high chemical stability and the large surface to volume ratio, extensive research within the fields of catalytic and sensor applications has been proposed [3-6]. In fact, multiwalled carbon nanotubes have been used as supports for $\mathrm{Co}-$ Mo-K catalyst for the selective formation of higher $\mathrm{C}_{2+}-$ alcohols from syngas $[5,7]$, as well as for hydrogenation of carbon monoxide over Co nanoparticles (Fisher-Tropsch synthesis) [6]. In order to enhance the chemical selectivity of gas sensors, the use of carbon nanotubes decorated with metal nanoparticles was proposed with promising results $[8,9]$. Nanocomposite of cobalt oxide nanoparticles and carbon nanotubes was also used for gas sensing devices with excellent results [10]. Cobalt-multiwalled carbon nanotubes (MWCNTs) composites were also used in microwave devices as absorbing materials [11].

In this work, high-quality MWCNTs were synthesized by the spray pyrolysis method. Subsequently, a wet chemistry process [12] was used in order to obtain nanostructured cobalt oxide particles by decomposition of the cobalt nitrate hexahydrate diluted in acetone and in the presence of carbon nanotubes. XPS results indicate the presence of cobalt oxide in the composite samples, while Raman spectroscopy studies confirmed the effective formation of cobalt oxide $\left(\mathrm{Co}_{3} \mathrm{O}_{4}\right)$. Transmission electron microscopy (TEM) imaging was performed as well as scanning transmission electron microscopy (STEM) measurements using a scanning electron microscopy equipped with a field emission gun (FEGSEM).

\section{Material and Methods}

2.1. Decoration of MWCNTs. The starting nanotube material was synthesized by the spray pyrolysis method as described elsewhere [12]. The advantage of this method is its capability to produce high yields of relatively clean nanotubes by the atomization of a solution released from a glass liquid container through a preheated quartz tube. A carrier gas is also required, and for this purpose an argon atmosphere with a flow rate of $1800 \mathrm{sccm}$ was used. In our experiments, ferrocene $\left(\mathrm{Fe}\left(\mathrm{C}_{5} \mathrm{H}_{5}\right)_{2}(\mathrm{~s})\right)$ dissolved in toluene $\left(\mathrm{C}_{7} \mathrm{H}_{8}\right)$ at a concentration of $2.3 \mathrm{wt} . \%$ was used. This solution was then pyrolyzed at $850^{\circ} \mathrm{C}$ in order to obtain MWCNTs with lengths 
up to several tens of micrometers and external diameters between 20 and $50 \mathrm{~nm}$. The nanotubes were collected by scratching the quartz tube walls and they were further characterized by Raman spectroscopy and TEM.

To create the nanoparticle decoration, the as-grown MWCNTs were first dispersed in a solution of cobalt nitrate in acetone at a concentration between 0.5 to $1.0 \mathrm{wt} . \%$. A twostep process was used to prepare the suspension. First, $25 \mathrm{mg}$ of MWCNTs were subjected to ultrasonic processing in an aqueous bath ultrasonication device (Metasom-14, $40 \mathrm{kHz}$ ) for 15 minutes. Subsequently, a magnetic stir bar was placed into the mixture; the mixture was stirred for 30 minutes to help disperse the nanotubes. This two-step process was repeated five times in order to maximize the dispersion and reduce possible damages to the MWCNTs. Next, in order to obtain cobalt oxide particles, the solution was then dehydrated at $300^{\circ} \mathrm{C}$ during two hours and later annealed in air at the same temperature for three hours according to the following reaction $\mathrm{Co}\left(\mathrm{NO}_{3}\right)_{2(s)} \cdot 6 \mathrm{H}_{2} \mathrm{O}_{(l)}+\mathrm{O}_{2(g)} \rightarrow \mathrm{Co}_{3} \mathrm{O}_{4}+$ $\mathrm{N}_{\mathrm{x}} \mathrm{O}_{\mathrm{y}(g)}+\mathrm{H}_{2} \mathrm{O}_{(l)}$.

2.2. Characterization. The Raman analyses were carried out using an NTEGRA Spectra-AFM/Confocal Raman microscope from NT-MDT equipped with a CCD detector. A laser line of $473 \mathrm{~nm}$ was used to excite the sample.

The chemical environment of the elements was determined by XPS. The photoelectron spectra of the C1s and Co2p core levels were monitored, using an Alpha 110 hemispherical analyzer from Thermo Scientific and a $\mathrm{Mg} \mathrm{K}_{\alpha} \mathrm{X}$ ray source $(h \nu=1253.6 \mathrm{eV})$. The pressure chamber was kept at about $10^{-6} \mathrm{~Pa}$ during analysis.

A careful TEM characterization was performed using a JEOL 2010 transmission electron microscope, whereas scanning electron microscopy (SEM) images were obtained using a JEOL scanning electron microscope (model JSM-6701F) equipped with a field emission gun and a STEM facility.

\section{Results and Discussion}

The first step was to monitor the quality of the nanotube material to be used for later experimentation. Figure 1 shows SEM and TEM images of the as-synthesized MWCNTs prior to the decoration experiments. The CNTs formed compact blocks of alignment carbon nanotube bundles, as shown in Figure 1(a). The SEM images also showed some lowcontrast regions corresponding to the presence of iron. It is noteworthy that amorphous carbon impurities were not usually evident and appeared in rare cases in our samples. The TEM image of the MWCNTs in Figure 1(b) reveals a heterogeneous diameter distribution and shows that many of the nanotubes were discontinuously filled with iron particles and iron nanowires, a common feature observed in samples prepared by spray pyrolysis [13].

Figure 2(a) shows a image obtained from a decorated MWCNT (0.5 wt.\% of cobalt nitrate in acetone) using the JEOL model JSM-6701F scanning electron microscope operating in STEM mode using a $30 \mathrm{keV}$ electron beam. The image shows particles with typical sizes of $50 \mathrm{~nm}$. STEM

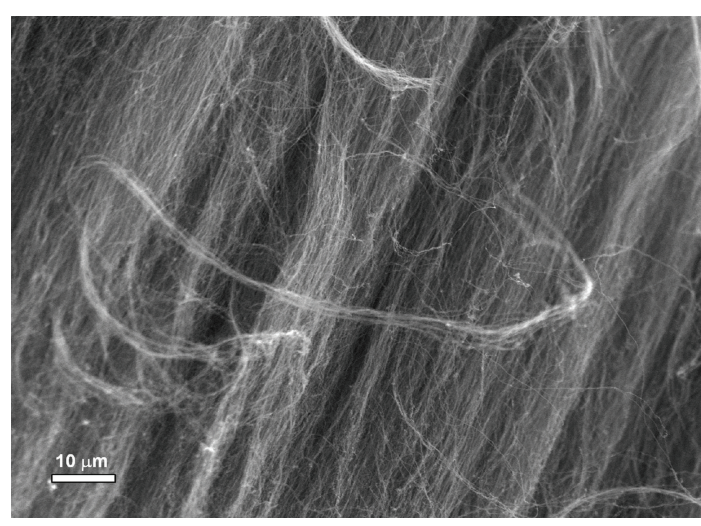

(a)

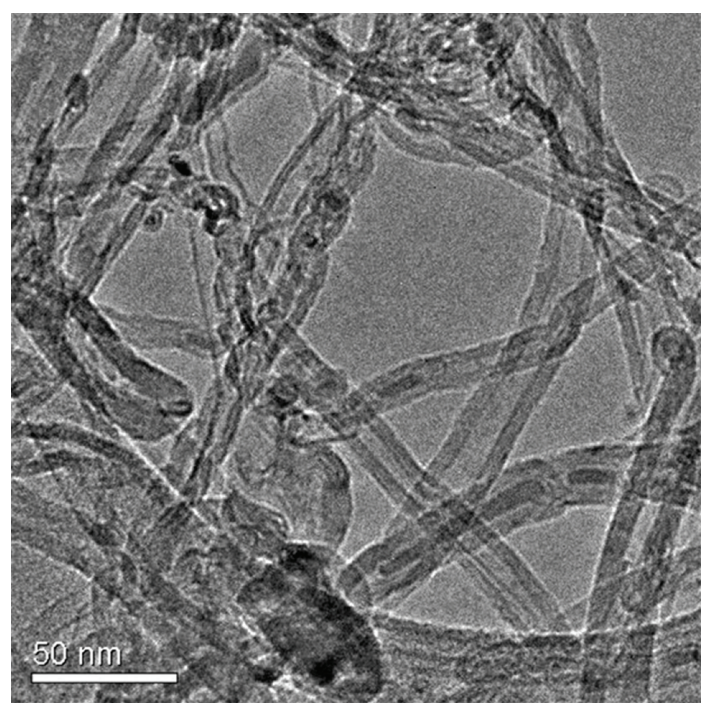

(b)

FIGURE 1: SEM and TEM images multi-walled carbon nanotubes prior to decoration experiments. (a) SEM image of as-grown MWCNTs. (b) TEM image obtained from as-grown MWCNTs.

images also show larger particles that can be clusters formed by two or three smaller particles. We observed no evident particle detachment from the tubes. Figure 2(b) shows the distribution of particle sizes obtained from several STEM images.

There is a sharp peak for particles with sizes of the order of $50 \mathrm{~nm}$, as revealed in Figure 2(a). Figure 3 shows the particle size distribution from a decorated MWCNT (1.0 wt.\%) obtained with the same procedure described above. The mean size increased with an increasing concentration of cobalt nitrate in acetone in the precursor mixture.

The cobalt concentration in the composite samples, as determined by XPS measurements, was 2.7 and 5.4 wt.\% for the MWCNTs decorated with cobalt nitrate concentrations of 0.5 and 1.0 wt. $\%$, respectively. Figure 4 shows the Co $2 p$ photoemission spectrum obtained from the nanoparticles/ MWCNTs (1.0 wt.\%) sample. The XPS spectrum presents two photoemission maxima at binding energies of $781.1 \mathrm{eV}$ for $2 p_{3 / 2}$ and $796.4 \mathrm{eV}$ for $2 p_{1 / 2}$. The satellite structures 


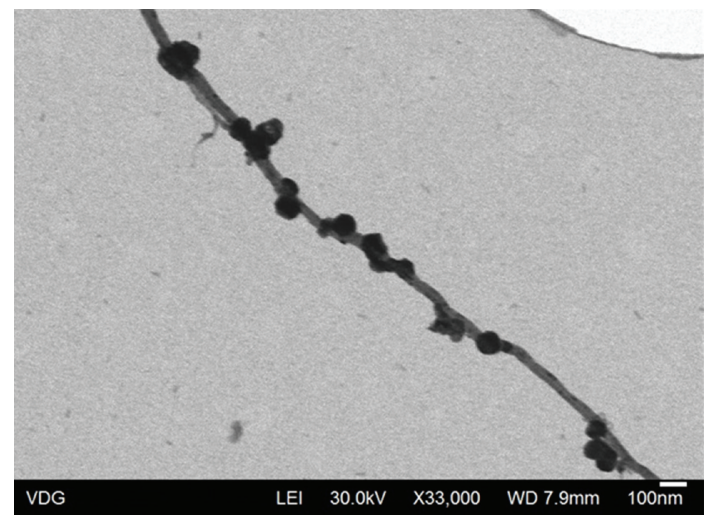

(a)

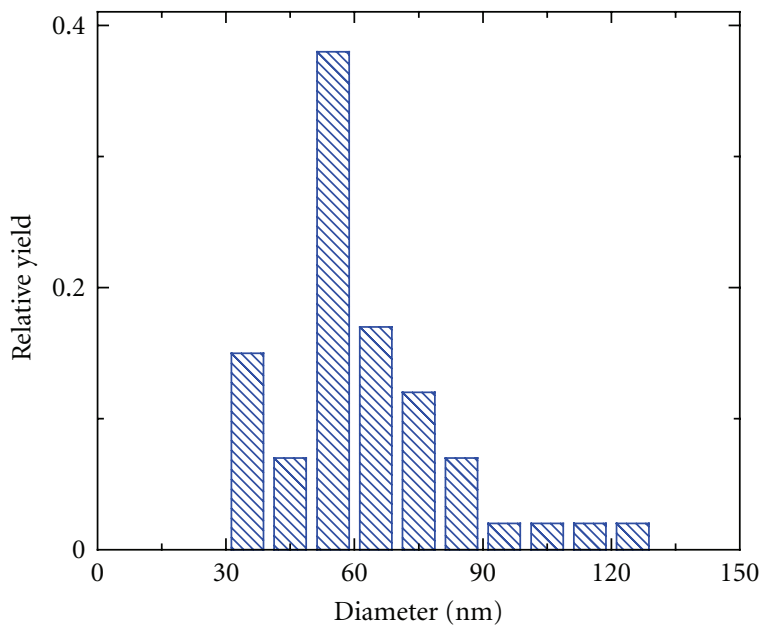

(b)

FIGURE 2: Characterization of multiwalled carbon nanotubes after decoration: (a) STEM image of a representative coated tube with Co oxide nanoparticles prepared with $0.5 \mathrm{wt} . \%$ of cobalt nitrate in acetone and (b) size distribution of Co oxide nanostructured particles attached to the walls of MWCNTs. The average size is around $50 \mathrm{~nm}$.

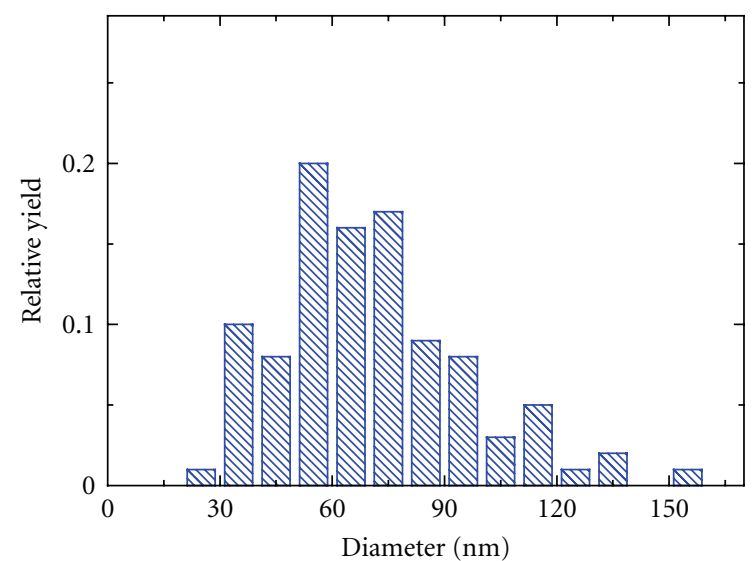

Figure 3: Size distribution of Co oxide nanostructured particles prepared with $1.0 \mathrm{wt} . \%$ of cobalt nitrate in acetone attached to the walls of MWCNTs. The average size is around $60 \mathrm{~nm}$.

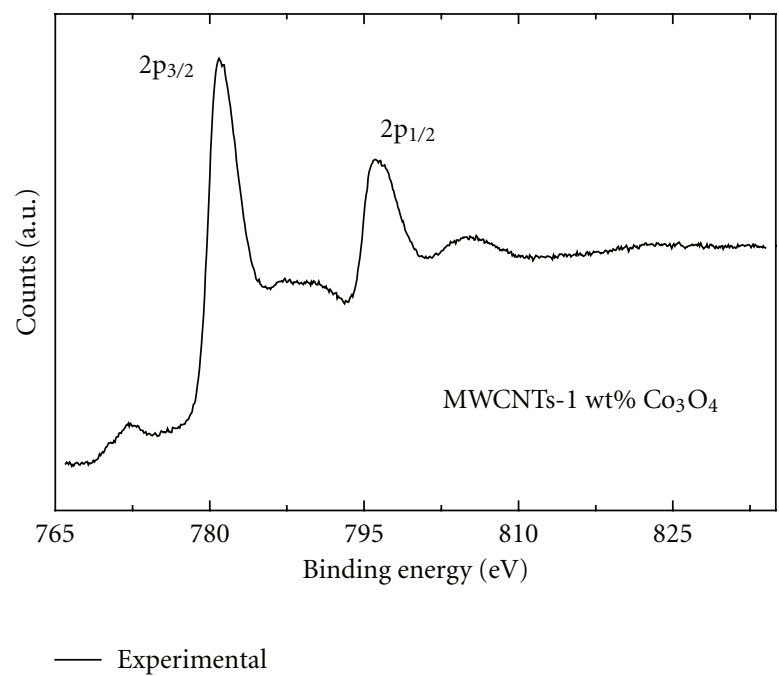

FIgURE 4: Co2p spectrum for the cobalt/MWCNT prepared with $1.0 \mathrm{wt} . \%$ of cobalt nitrate in acetone after decoration process.

appeared at around $789 \mathrm{eV}$ for $2 p_{3 / 2}$ and at $805 \mathrm{eV}$ for $2 p_{1 / 2}$. The satellite structures should be attributed to shake-up lines. The binding energies were calibrated relative to the CNTs C1s peak at $285.2 \mathrm{eV}$ to compensate for charging and work function effects. The energy of the $\mathrm{Co} 2 p_{3 / 2}$ peak for metallic cobalt is $778.3 \mathrm{eV}$ [14].

However, in Figure 4, the position of the main peak in the Co2p photoemission spectrum is shifted to a higher binding energy indicating the presence of cobalt oxides. The identification of cobalt oxides was not easy because of the small chemical shift of the main peaks in the XPS spectra of $\mathrm{Co} 2 p$ electrons in $\mathrm{Co}^{2+}$ and $\mathrm{Co}^{3+}$ as well as quite similar satellite structures. However, intensity ratio of Co $2 p_{1 / 2}$ satellite to its main peak was used to distinguish the monoxide and the spinel. It has been reported that the intensity ratio of $\mathrm{Co} 2 p_{1 / 2}$ to its mains peak is $\sim 0.9$ for cubic $\mathrm{CoO}$ and $\sim 0.3$ for $\mathrm{Co}_{3} \mathrm{O}_{4}$. From the spectra obtained from our samples, this ratio is around 0.3 in a clear indication that $\mathrm{Co}_{3} \mathrm{O}_{4}$ was formed [15].

The Raman spectrum acquired from the as-grown sample is presented in Figure 5(a).

The peaks at $\sim 1350$ and $\sim 1580 \mathrm{~cm}^{-1}$ can be ascribed to the well-known $\mathrm{D}$ and $\mathrm{G}$ bands of carbon nanotubes, respectively. The second-order peak at $\sim 2750 \mathrm{~cm}^{-1}$ is called $2 \mathrm{D}$ band. The Raman spectra taken from MWCNTs decorated with cobalt oxide particles show the same characteristic peaks at approximately the same positions, as is clear in Figures 5(b) and 5(c). The Raman method was effectively used to investigate the cobalt oxide structures in our samples. In fact, the spectrum presented in Figure 5(b) shows four typical peaks of $\mathrm{Co}_{3} \mathrm{O}_{4}$ around $469,511,606$, and $673 \mathrm{~cm}^{-1}$. This spectrum was obtained from the decorated sample prepared with $0.5 \mathrm{wt} . \%$ of cobalt nitrate in acetone. It confirms the interaction between $\mathrm{Co}^{2+}$ and carbon nanotubes and matches up well with the reported cobalt oxide spectrum [16]. The intensity of the $\mathrm{Co}_{3} \mathrm{O}_{4}$ bands increased with an increasing concentration of cobalt nitrate in acetone. 


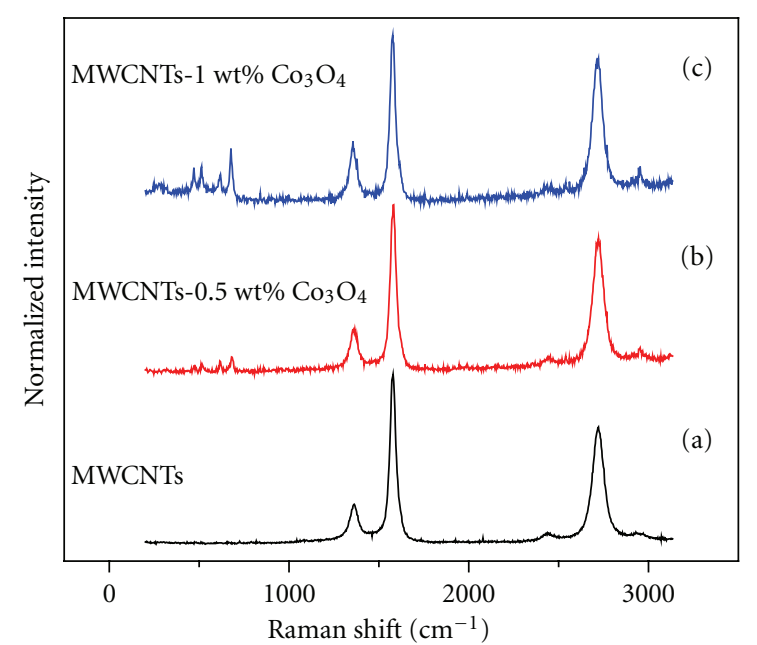

FIGURE 5: Raman spectra taken for as-grown and decorated MWCNTs. (a) Pure MWCNT grown at 2.3 wt.\% of ferrocene in toluene by spray pyrolysis, (b)-(c) cobalt oxide nanoparticles/MWCNT composites.

The $I_{D} / I_{G}$ ratio represents the amorphous phase content or the degree of crystallinity of the carbonaceous materials and is a good indicator of the quality of the samples [17]. Raman spectroscopy indicated that the formation of particles on the MWCNTs was achieved with some disruption of the graphitic CNTs; the $I_{D} / I_{G}$ varied from 0.19 for pure MWCNTs to 0.25 and 0.35 for the composite samples prepared with 0.5 and $1.0 \mathrm{wt} . \%$ of cobalt nitrate in acetone, respectively.

Figures 6(a) and 6(b) show TEM images of cobalt particles $(50 \mathrm{~nm})$ on top of decorated MWCNTs (1.0 wt.\%) MWCNTs. The images reveal that in some cases the particles are on locally damaged tube walls, as is clear from Figure 6(b). The coating etched the external tube walls during particle growth. These defects are probably responsible for the observed increase of the $I_{D} / I_{G}$ upon the increase of cobalt nitrate in the precursor mixture.

The microscopy images suggested that the presence of active sites on the MWCNTs walls could favor the nucleation and growth of cobalt nanoparticles on the surface. The dissociation of $\mathrm{Co}\left(\mathrm{NO}_{3}\right)_{2}$ in acetone could oxidize the external walls of MWNCTs creating an oxide layer on the tube interface; this mechanism could be responsible for an efficient particle anchoring [18].

\section{Conclusions}

In conclusion, we have demonstrated that carbon nanotubes can be decorated by cobalt oxide nanoparticles through a simple chemical route, which is being potentially useful for catalytic and sensor applications. The nanoparticles were strongly anchored to the outer wall of the nanotubes, in few cases forming agglomerations in specific regions and partially etching the tube in such a way that the structural quality of the nanotubes was not drastically affected. The concentration of surface defects in our samples was probably

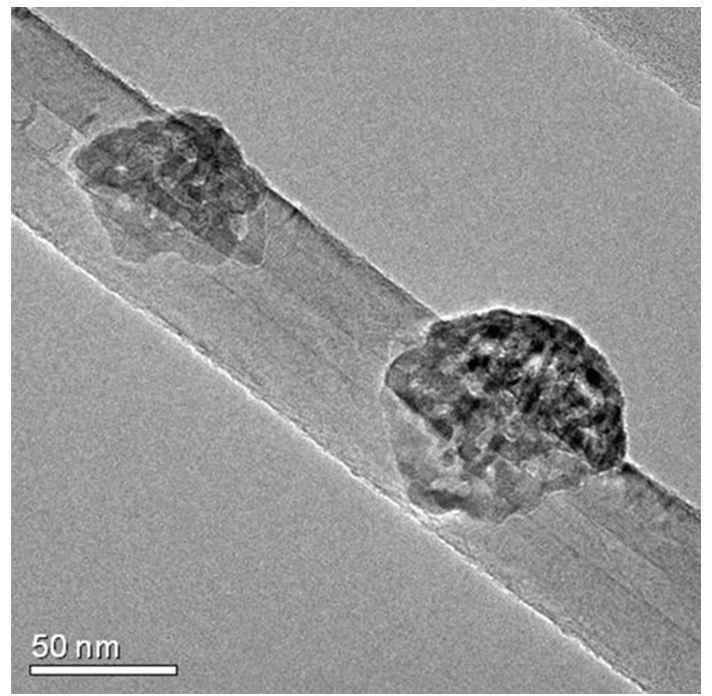

(a)

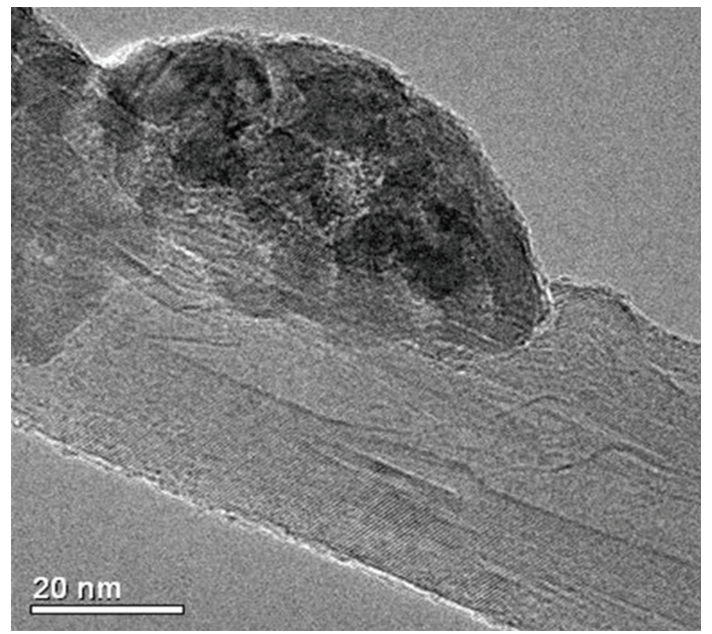

(b)

FIgURE 6: TEM images of MWCNTs decorated with cobalt oxide nanoparticles prepared with $1.0 \mathrm{wt} . \%$ of cobalt nitrate in acetone.

the key factor driving the quite homogeneous distribution of the catalytic cobalt in the tube walls. XPS and Raman confirmed $\mathrm{Co}_{3} \mathrm{O}_{4}$ as the main oxide formed during the decoration process.

\section{Acknowledgments}

The authors acknowledge the financial support from the Brazilian Agencies, Conselho Nacional de Desenvolvimento Científico e Tecnológico (CNPq) and Fundação de Amparo à Pesquisa do Estado do Rio de Janeiro (FAPERJ).

\section{References}

[1] M. Endo, M. S. Strano, and P. M. Ajayan, "Potential applications of carbon nanotubes," in Carbon Nanotubes: Advanced Topics in the Synthesis, Structure, Properties and Applications, 
A. Jorio, M. S. Dresselhaus, and G. Dresselhaus, Eds., pp. 1361, Springer, Berlin, 2008.

[2] M. Terrones, "Science and technology of the twenty-first century: synthesis, properties, and applications of carbon nanotubes," Annual Review of Materials Research, vol. 33, pp. 419501, 2003.

[3] T. Zhang, S. Mubeen, N. V. Myung, and M. A. Deshusses, "Recent progress in carbon nanotube-based gas sensors," Nanotechnology, vol. 19, no. 33, Article ID 332001, 2008.

[4] A. L. M. Reddy, N. Rajalakshmi, and S. Ramaprabhu, "Cobaltpolypyrrole-multiwalled carbon nanotube catalysts for hydrogen and alcohol fuel cells," Carbon, vol. 46, no. 1, pp. 2-11, 2008.

[5] X.-M. Wu, Y.-Y. Guo, J.-M. Zhou, G.-D. Lin, X. Dong, and H.B. Zhang, "Co-decorated carbon nanotubes as a promoter of Co-Mo-K oxide catalyst for synthesis of higher alcohols from syngas," Applied Catalysis A, vol. 340, no. 1, pp. 87-97, 2008.

[6] J. Lv, X. Ma, S. Bai, C. Huang, Z. Li, and J. Gong, "Hydrogenation of carbon monoxide over cobalt nanoparticles supported on carbon nanotubes," International Journal of Hydrogen Energy, vol. 36, no. 14, pp. 8365-8372, 2011.

[7] V. R. Surisetty, A. K. Dalai, and J. Kozinski, "Synthesis of higher alcohols from synthesis gas over Co-promoted alkalimodified MoS2 catalysts supported on MWCNTs," Applied Catalysis A, vol. 385, no. 1-2, pp. 153-162, 2010.

[8] A. Star, V. Joshi, S. Skarupo, D. Thomas, and J. C. P. Gabriel, "Gas sensor array based on metal-decorated carbon nanotubes," Journal of Physical Chemistry B, vol. 110, no. 42, pp. 21014-21020, 2006.

[9] R. V. Gelamo, F. P. Rouxinol, C. Verissimo, A. R. Vaz, M. A. Bica de Moraes, and S. A. Moshkalev, "Low-temperature gas and pressure sensor based on multi-wall carbon nanotubes decorated with Ti nanoparticles," Chemical Physics Letters, vol. 482, no. 4-6, pp. 302-306, 2009.

[10] W. Li, H. Jung, N. D. Hoa, D. Kim, S. K. Hong, and H. Kim, "Nanocomposite of cobalt oxide nanocrystals and singlewalled carbon nanotubes for a gas sensor application," Sensors and Actuators B, vol. 150, no. 1, pp. 160-166, 2010.

[11] B. Tianjiao, Z. Yan, S. Xiaofeng, and D. Yuexin, "A study of the electromagnetic properties of Cobalt-multiwalled carbon nanotubes (Co-MWCNTs) composites," Materials Science and Engineering B, vol. 176, no. 12, pp. 906-912, 2011.

[12] P. Ayala, F. L. Freire, L. Gu et al., "Decorating carbon nanotubes with nanostructured nickel particles via chemical methods," Chemical Physics Letters, vol. 431, no. 1-3, pp. 104109, 2006.

[13] R. Kamalakaran, M. Terrones, T. Seeger et al., "Synthesis of thick and crystalline nanotube arrays by spray pyrolysis," Applied Physics Letters, vol. 77, no. 21, pp. 3385-3387, 2000.

[14] C. Ruby, J. N. Zhou, J. Du, S. C. Street, and J. Barnard, "Surface characterization of $\mathrm{Co} / \mathrm{CNx}$ granular films fabricated by nanolamination," Surface and Interface Analysis, vol. 29, no. 1, pp. 38-45, 2000.

[15] W. Z. Wang and G. L. Zhang, "Synthesis and optical properties of high-purity $\mathrm{CoO}$ nanowires prepared by an environmentally friendly molten salt route," Journal of Crystal Growth, vol. 311, no. 17, pp. 4275-4280, 2009.

[16] V. G. Hadjiev and M. N. Iliev, "Polarized Raman spectra of superconducting $\mathrm{YBa}_{2} \mathrm{Cu}_{3} \mathrm{O}_{7}$ single microcrystals," Solid State Communications, vol. 66, no. 4, pp. 451-453, 1988.

[17] M. S. Dresselhaus, G. Dresselhaus, R. Saito, and A. Jorio, "Raman spectroscopy of carbon nanotubes," Physics Reports, vol. 409, no. 2, pp. 47-99, 2005.
[18] P. Martis, B. R. Venugopal, J. Delhalle, and Z. Mekhalif, "Selective decoration of nickel and nickel oxide nanocrystals on multiwalled carbon nanotubes," Journal of Solid State Chemistry, vol. 184, no. 5, pp. 1245-1250, 2011. 

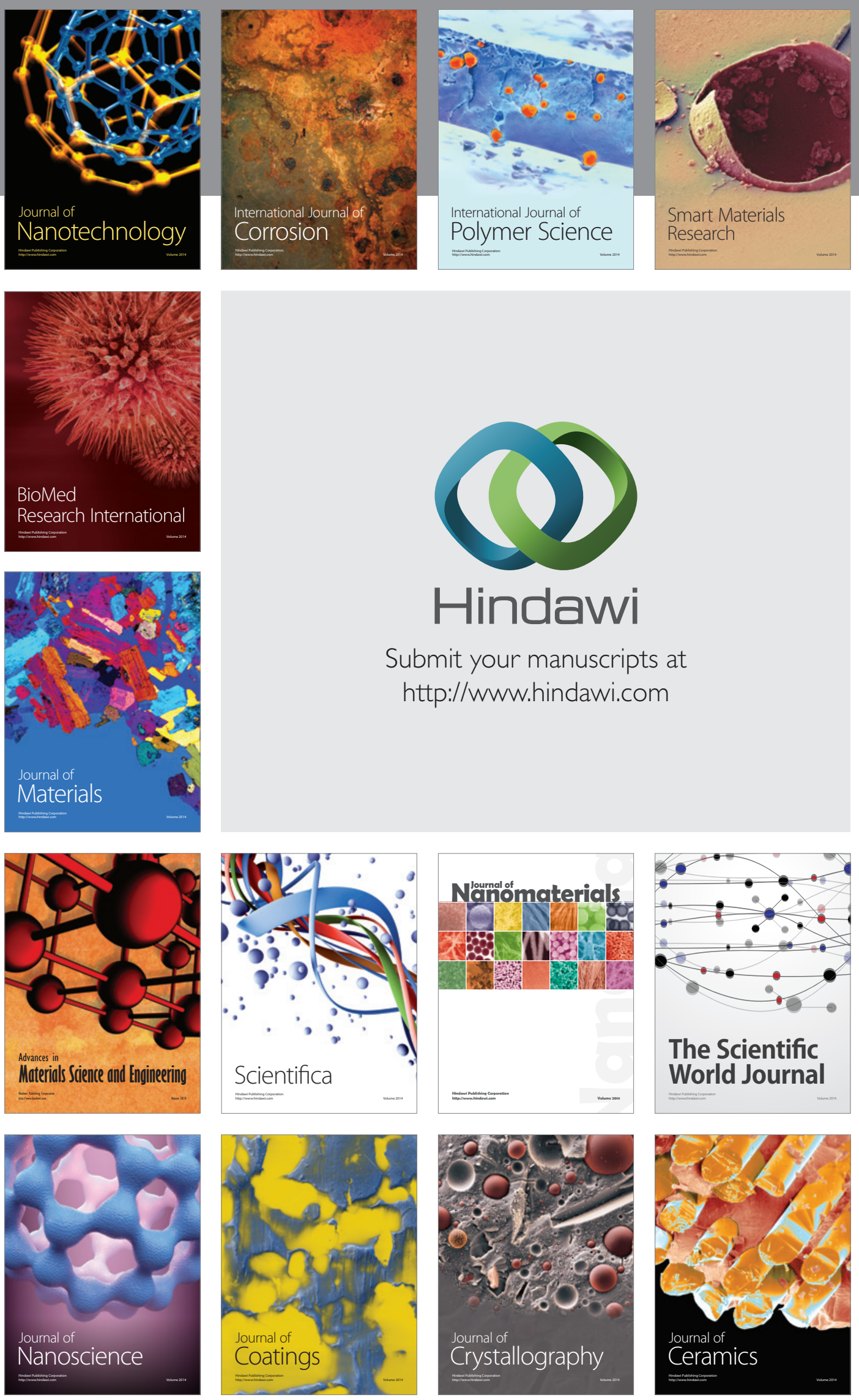

The Scientific World Journal

Submit your manuscripts at

http://www.hindawi.com

\section{World Journal}

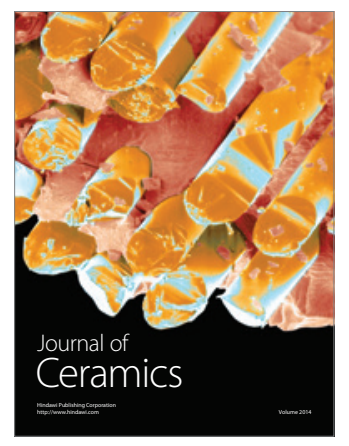

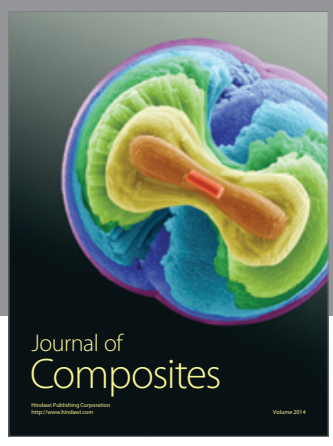
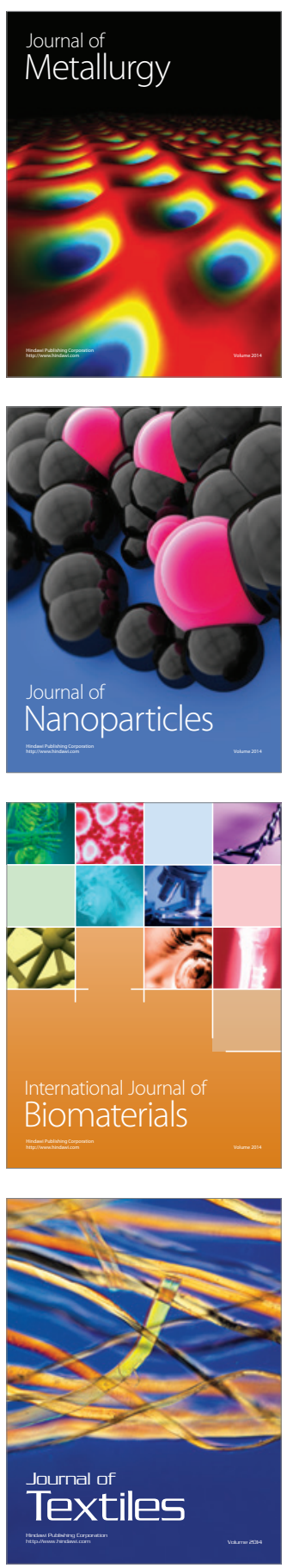